Pacific Journal of Mathematics

ZERO DISTRIBUTION OF FUNCTIONS WITH SLOW OR 


\title{
ZERO DISTRIBUTION OF FUNCTIONS WITH SLOW OR MODERATE GROWTH IN THE UNIT DISC
}

\author{
L. R. SONS
}

We consider functions which are analytic or meromorphic in the unit disc $D$. Our concern is to obtain information about values a function may assume when we know the function satisfies certain growth conditions. For analytic functions whose growth measured by two related growth indicators is distinct, we explore conditions under which this distinctness leads to the presence of zeros for the functions.

Let $f$ be a meromorphic function in $D$. We shall assume knowledge of the usual functions of Nevanlinna theory as in [1]. In addition we define $m_{2}(r, f)$ for $0<r<1$ by

$$
m_{2}(r, f)=\left\{\frac{1}{2 \pi} \int_{0}^{2 \pi}\left(\log \left|f\left(r e^{i \theta}\right)\right|\right)^{2} d \theta\right\}^{1 / 2} .
$$

A number of properties of $m_{2}(r, f)$ and some value distribution theorems involving $m_{2}(r, f)$ appear in [5]. We further define $\alpha$ and $\tilde{\alpha}$ by

$$
\alpha=\limsup _{r \rightarrow 1} \frac{\log m_{2}(r, f)}{-\log (1-r)}
$$

and

$$
\tilde{\alpha}=\limsup _{r \rightarrow 1} \frac{\log T(r, f)}{-\log (1-r)},
$$

where $T(r, f)$ is the value of the Nevanlinna characteristic function at $r$. (Of course $\alpha$ and $\tilde{\alpha}$ depend on $f$, but as we use them no confusion should result from suppressing that dependence, since we are ordinarily dealing with one function at a time.) In this paper we assume $\alpha<+\infty$. We prove the following theorem.

THEOREM 1. Let $f$ be an analytic function in $D$. Then $\tilde{\alpha} \leqq \alpha \leqq$ $\tilde{\alpha}+1 / 2$.

If we consider $f$ defined in $D$ by $\exp ((1+z) /(1-z))$, it can be shown that $\tilde{\alpha}=0$ and $\alpha=1 / 2$. It is also possible to construct Blaschke products in $D$ for which $0<\alpha<1 / 2$ [cf. 2].

For an arbitrary meromorphic function $f$ in $D$ it will be convenient to define $I_{1}(r)$ and $I_{2}(r)$ for $0<r<1$ by 


$$
I_{1}(r)=\int_{0}^{2 \pi}\left|\frac{f^{\prime}\left(r e^{i \theta}\right)}{f\left(r e^{i \theta}\right)}\right| d \theta,
$$

and

$$
I_{2}(r)=\int_{0}^{2 \pi}\left|\frac{f^{\prime}\left(r e^{i \theta}\right)}{f\left(r e^{i \theta}\right)}\right|^{2} d \theta
$$

We shall show:

THEOREM 2. Let $f$ be a meromorphic function in D. Assume $f$ has at most a finite number of zeros and poles in $D$. Also assume $\alpha>0$.

(i ) If $I_{1}(r)=0\left((1-r)^{-\beta}\right),(r \rightarrow 1)$, then $\beta \geqq \alpha$.

(ii) If $I_{2}(r)=0\left((1-r)^{-\beta}\right),(r \rightarrow 1)$, then $\beta \geqq 2 \alpha$.

We now turn to results about value distribution. Our main concern is to obtain conclusions about the values assumed by a function for which $\tilde{\alpha}<\alpha$. Our theorems allow $\tilde{\alpha}=0$, so they apply to functions which are bounded in $D$ for which $\alpha>0$ or to functions which have bounded characteristic in $D$ for which $\alpha>0$. We have:

THEOREM 3. Let $f$ be an analytic function in $D$ for which $0 \leqq \tilde{\alpha}<\alpha$. Suppose $f$ has at most a finite number of zeros. Assume further that

$$
I_{1}(r)=0\left((1-r)^{-\beta}\right), \quad(r \longrightarrow 1),
$$

where $\beta+\tilde{\alpha}<2 \alpha$. Then for each $\theta, 0 \leqq \theta<2 \pi$,

$$
|\log | f\left(r e^{i \theta}\right)|| \neq 0\left((1-r)^{-r}\right), \quad(r \longrightarrow 1),
$$

where $\gamma<2 \alpha-\tilde{\alpha}$.

Corollaries of special interest are:

CoROLlary 1. Let $f$ be an analytic function in $D$ for which $\tilde{\alpha}<\alpha$. Assume further that (1.1) holds where $\beta+\tilde{\alpha}<2 \alpha$. If $f$ has a finite nonzero radial asymptotic path in $D$, then $f$ has infinitely many zeros.

CoROllary 2. Let $f$ be an analytic function in $D$ for which $\tilde{\alpha}<\alpha$. Assume $f$ has at most a finite number of zeros in $D$ and $I_{1}(r)=0\left((1-r)^{-\beta}\right),(r \rightarrow 1)$. If $f$ has a finite nonzero radial asymptotic path in $D$, then $\beta \geqq 2 \alpha-\tilde{\alpha}$.

Corollary 2 should be compared with (i) of Therem 2 . 
Corollary 3. Let $f$ be an analytic function in $D$ which has bounded characteristic. Suppose $\alpha>0$. Assume $f$ has at most a finite number of zeros. If $I_{1}(r)=0\left((1-r)^{-\beta}\right),(r \rightarrow 1)$, then $\beta \geqq 2 \alpha$.

A second major result concerning value distribution is:

THEOREM 4. Let $f$ be an analytic function in $D$ for which $0 \leqq \tilde{\alpha}<\alpha$. Assume further that

$$
I_{2}(r)=0\left((1-r)^{-\beta}\right), \quad(r \longrightarrow 1),
$$

where $\beta<2+2 \alpha$. Then $f$ has an infinite number of zeros in $D$.

If we expect to conclude the presence of zeros for analytic functions in $D$ for which $\tilde{\alpha}<\alpha$, it is clear that a condition such as (1.1) or (1.2) is necessary when one considers the function $f$ defined in $D$ by $f(z)=\exp ((1+z) /(1-z))$. For this $f$ it can be shown that $\widetilde{\alpha}=0 ; \alpha=1 / 2 ; I_{1}(r) \sim C_{1}(1-r)^{-1}$; and $I_{2}(r) \sim C_{2}(1-r)^{-3}$ where $C_{1}$ and $C_{2}$ are constants. The corollaries below are immediate consequences of Theorem 4. It is interesting to compare them with (ii) of Theorem 2.

Corollary 4. Let $f$ be an analytic function in D. Assume $\tilde{\alpha}<\alpha$. Assume further that $f$ has at most a finite number of zeros in D. If $I_{2}(r)=0\left((1-r)^{-\beta}\right),(r \rightarrow 1)$, then $\beta \geqq 2 \alpha+2$.

Corollary 5. Let $f$ be an analytic function in D. Assume $\alpha>0$, and suppose $f$ has no zeros in $D$. If $I_{2}(r)=0\left((1-r)^{-\beta}\right)$, $(r \rightarrow 1)$, then $\beta \geqq 2 \alpha+2$.

One might suspect that for an analytic function in $D$ for which the orders satisfy $\tilde{\alpha}<\alpha$ that it might be possible to conclude that the zeros of such a function could not be uniformly distributed about the circumference of the unit circle. However the function $g$ defined in $D$ by

$$
g(z)=\left(\exp \left(\frac{1+z}{1-z}\right)\right) B(z)
$$

where $B(z)$ is the Blaschke product constructed in [3, p. 599] by G. MacLane and L. Rubel has $\tilde{\alpha}=0$ and $\alpha=1 / 2$ and zeros rather uniformly distributed, so any theorem in the direction suggested would have to be rather refined.

The remaining sections contain the proofs of the theorems in order.

2. Proof of Theorem 1. Without loss of generality we assume 
$f(o)=1$. In [4] it was shown that

$$
m_{2}(r, f) \leqq\{1+(8 \sqrt{\log 2)} / \sqrt{\log (R / r)\}} T(R, f), \quad(0<r<R) .
$$

Thus, if we let $C=8 \sqrt{\log 2}, R=(1 / 2)(1+r)$, and observe that

$$
\log \left(1+\frac{1-r}{2 r}\right) \geqq \frac{1-r}{4 r}, \quad\left(r_{0}<r<1\right)
$$

we see

$$
m_{2}(r, f) \leqq\left\{1+2 C\left(\frac{1}{1-r}\right)^{1 / 2}\right\} T\left(\frac{1}{2}(1+r), f\right), \quad\left(r_{0}<r<1\right) .
$$

Hence $\alpha \leqq \tilde{\alpha}+1 / 2$.

To see that $\tilde{\alpha} \leqq \alpha$, we use Schwarz's inequality to get

$$
\frac{1}{2 \pi} \int_{0}^{2 \pi}|\log | f\left(r e^{i \rho}\right) \| d \theta \leqq m_{2}(r, f) .
$$

But the First Fundamental Theorem of Nevanlinna theory then shows

$$
2 T(r, f)-N(r, 1 / f)=\frac{1}{2 \pi} \int_{0}^{2 \pi}|\log | f\left(r e^{i \theta}\right) \| d \theta .
$$

Therefore,

$$
T(r, f) \leqq m_{2}(r, f),
$$

and the desired inequality follows.

3. Proof of Theorem 2. We assume $f(o)=1$. We first observe [cf. 5] that for $0<r<1$

$$
m_{2}(r, f)=\left\{\sum_{k=-\infty}^{\infty}\left|c_{k}(r)\right|^{2}\right\}^{1 / 2}
$$

where

$$
c_{k}(r)=\frac{1}{2 \pi} \int_{0}^{2}\left(\log \left|f\left(r e^{i 0}\right)\right|\right) e^{-i k \theta} d \theta .
$$

We note that $c_{k}(r)=\overline{c_{-k}(r)}$ and $c_{0}(r)=N(r, 1 / f)-N(r, f)$. Thus, for $0<r<1$,

$$
m_{2}(r, f)=\left\{(N(r, 1 / f)-N(r, f))^{2}+2 \sum_{k=1}^{\infty}\left|c_{k}(r)\right|^{2}\right\}^{1 / 2} .
$$

Now for integral $k$ define $H_{k}(r)$ by

$$
H_{k}(r)=\frac{1}{2 \pi} \int_{0}^{2 \pi}\left(\log f\left(r e^{i \theta}\right)\right) e^{-i k \theta} d \theta, \quad(0<r<1) .
$$


Then for $k \geqq 1$,

$$
2 c_{k}(r)=H_{k}(r)+\overline{H_{-k}(r)}, \quad(0<r<1) .
$$

Using integration by parts, we can write for $k \geqq 1$ and $0<r<1$ that

$$
H_{k}(r)=-\frac{1}{k}(n(r, 1 / f)-n(r, f))+\frac{r^{k}}{k} \frac{1}{2 \pi i} \int_{|z|=r} \frac{f^{\prime}(z)}{f(z)} \frac{d z}{z^{k}}
$$

and

$$
H_{-k}(r)=\frac{1}{k}(n(r, 1 / f)-n(r, f))-\frac{1}{k r^{k}} \cdot \frac{1}{2 \pi i} \int_{|z|=r} \frac{f^{\prime}(z)}{f(z)} z^{k} d z .
$$

From (3.2), $(3,3)$, and (3.4) we see for $k \geqq 1$ and $0<r<1$ that

$$
2 c_{k}(r)=\frac{1}{k} r^{k} \frac{1}{2 \pi i} \int_{|z|=r} \frac{f^{\prime}(z)}{f(z)} \frac{d z}{z^{k}}-\frac{1}{k} \frac{1}{r^{k}} \frac{1}{2 \pi i} \int_{|z|=r} \frac{f^{\prime}(z)}{f(z)} z^{k} d z .
$$

And so taking absolute values and making standard estimates, we have for $0<r<1$

$$
2\left|c_{k}(r)\right| \leqq \frac{1}{k} \frac{2}{2 \pi} \int_{0}^{2 \pi}\left|\frac{f^{\prime}\left(r e^{i \theta}\right)}{f\left(r e^{i \theta}\right)}\right| d \theta, \quad(k \geqq 1) .
$$

Therefore, if $I_{1}(r)=0\left((1-r)^{-\beta}\right),(r \rightarrow 1)$, then there is a constant $A_{1}$ such that (3.5) implies

$$
\left|c_{k}(r)\right| \leqq \frac{1}{k} A_{1}(1-r)^{-\beta}, \quad(k \geqq 1), \quad(0<r<1) .
$$

Combining (3.1) and (3.6), we find

$$
\begin{array}{r}
m_{2}(r, f) \leqq\left\{(N(r, 1 / f)-N(r, f))^{2}+\sum_{k=1}^{\infty}\left\{\frac{1}{k^{2}}\left(A_{1}\right)^{2}(1-r)^{-2 \beta}\right\}\right\}^{1 / 2}, \\
(0<r<1) .
\end{array}
$$

Hence there is a constant $A_{2}$ such that (3.7) becomes

$$
m_{2}(r, f)^{2} \leqq(N(r, 1 / f)-N(r, f))^{2}+A_{2}(1-r)^{-2 \beta}, \quad(0<r<1) .
$$

On the other hand we know for $0<r<1$ that

$$
n(r, 1 / f)-n(r, f)=\frac{1}{2 \pi i} \int_{|z|=r} \frac{f^{\prime}(z)}{f(z)} d z,
$$

and

$$
|n(r, 1 / f)-n(r, f)| \leqq I_{1}(r), \quad(0<r<1) .
$$

We also have 


$$
\begin{aligned}
|N(r, 1 / f)-N(r, f)| & =\left|\int_{0}^{r} \frac{n(t, 1 / f)-n(t, f)}{t} d t\right|, \\
& \leqq \int_{0}^{r} \frac{|n(t, 1 / f)-n(t, f)|}{t} d t, \quad(0<r<1) .
\end{aligned}
$$

Combining (3.9) with (3.10) and the assumption $f(0)=1$, we see there are constants $K_{1}$ and $K$ such that

$$
|N(r, 1 / f)-N(r, f)| \leqq K_{1} \int_{1 / 2}^{r} I_{1}(t) d t+K, \quad\left(\frac{1}{2}<r<1\right) .
$$

Thus, if $I_{1}(r)=0\left((1-r)^{-\beta}\right),(r \rightarrow 1)$, there are constants $K_{2}, K_{3}$, and $K_{4}$ such that (3.11) yields for $1 / 2<r<1$

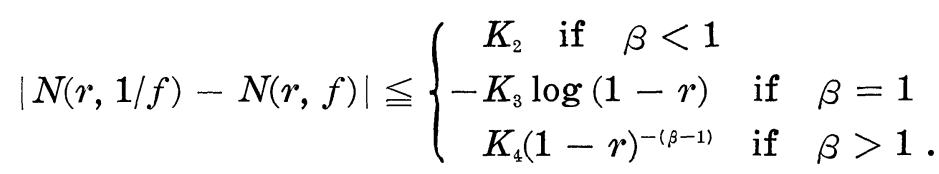

Now if $\beta<\alpha$ we find (3.8) and (3.12) taken together lead to a contradiction. Hence $\beta \geqq \alpha$, and (i) is proved.

To see (ii) is true, we first observe that there is a constant $K_{5}$ such that

$$
I_{1}(r) \leqq K_{5}\left(I_{2}(r)\right)^{1 / 2}, \quad(0<r<1) .
$$

So if $I_{2}(r)=0\left((1-r)^{-\beta}\right),(r \rightarrow 1)$, then

$$
I_{1}(r)=0\left((1-r)^{-\beta / 2}\right), \quad(r \longrightarrow 1) .
$$

Part (i) and (3.13) imply $\beta \geqq 2 \alpha$.

4. Proof of Theorem 3. Assume first that $f$ has no zeros in $D, f(o)=1$, and let $0<r<R<1$. If $z=r e^{i \theta}$, then the PoissonJensen formula shows

$$
\log |f(z)|=\frac{1}{2 \pi} \int_{0}^{2 \pi} \frac{\left(R^{2}-r^{2}\right) \log \left|f\left(R e^{i \phi}\right)\right|}{R^{2}-2 R r \cos (\phi-\theta)+r^{2}} d \phi
$$

Multiplying both sides by $(1 /(2 \pi)) \log |f(z)|$ and integrating with respect to $\theta$ over the interval $[0,2 \pi]$, we get

$$
m_{2}(r, f)^{2}=\frac{1}{2 \pi} \int_{0}^{2 \pi}\left(\frac{1}{2 \pi} \int_{0}^{2 \pi} \frac{\left(R^{2}-r^{2}\right) \log \left|f\left(R e^{i \phi}\right)\right|}{R^{2}-2 R r \cos (\phi-\theta)+r^{2}} d \phi\right)\left(\log \left|f\left(r e^{i \theta}\right)\right|\right) d \theta .
$$

An integration by parts on the right-hand side gives

$$
m_{2}(r, f)^{2}=\left(\frac{1}{2 \pi} \int_{0}^{2 \pi} \frac{\left(R^{2}-r^{2}\right) \log \left|f\left(R e^{i \phi}\right)\right|}{R^{2}-2 R r \cos \phi+r^{2}} d \phi\right)\left(\frac{1}{2 \pi} \int_{0}^{2 \pi}\left(\log \left|f\left(r e^{i \theta}\right)\right|\right) d \theta\right)
$$




$$
\begin{aligned}
& +\int_{0}^{2 \pi}\left(\int_{0}^{\theta} \frac{1}{2 \pi}\left(\log \left|f\left(r e^{i \theta}\right)\right|\right) d \theta\right) \\
& \times\left(\frac{1}{2 \pi} \int_{0}^{2 \pi} \frac{\left(R^{2}-r^{2}\right)\left(\log \left|f\left(R e^{i \phi}\right)\right|((2 R r \sin (\phi-\theta))\right.}{\left(R^{2}-2 R r \cos (\phi-\theta)+r^{2}\right)^{2}} d \phi\right) d \theta .
\end{aligned}
$$

Using the Poisson-Jensen formula and the differentiated formula, the latter may be rewritten as

$$
\begin{aligned}
m_{2}(r, f)^{2}= & (\log |f(r)|)\left(\frac{1}{2 \pi} \int_{0}^{2 \pi}\left(\log \left|f\left(r e^{i \theta}\right)\right|\right) d \theta\right) \\
& +\int_{0}^{2 \pi}\left(\int_{0}^{\theta} \frac{1}{2 \pi}\left(\log \left|f\left(r e^{i \theta}\right)\right|\right) d \theta\right)\left(\operatorname{Im} r e^{i \theta} \frac{f^{\prime}\left(r e^{i \theta}\right)}{f\left(r e^{i \theta}\right)}\right) d \theta .
\end{aligned}
$$

Standard inequalities then imply

$$
m_{2}(r, f)^{2} \leqq 2 T(r, f)\left\{|\log | f(r) \|+\int_{0}^{2 \pi}\left|\frac{f^{\prime}\left(r e^{i \theta}\right)}{f\left(r e^{i \theta}\right)}\right| d \theta\right\} .
$$

For each $\varepsilon>0,(1.1)$ and the definition of $\tilde{\alpha}$ enable us to obtain

$$
m_{2}(r, f)^{2}=0\left((1-r)^{-(\tilde{\alpha}+\varepsilon)}\right)\left\{|\log | f(r) \|+(1-r)^{-\beta}\right\}, \quad(r \longrightarrow 1) .
$$

Since $\beta+\tilde{\alpha}<2 \alpha$, we conclude from (4.1) that the conclusion is true for $\theta=0$. A simple rotation shows it to be valid for each $\theta$. (Actually the bound in (4.1) is uniform with respect to $\theta$.)

If $f$ has zeros in $D$, we let $\left\{a_{n}\right\}$ be the zeros and $r_{0}$ such that $\left|a_{n}\right|<r_{0}<1$ for all $n$. Let $0<r_{0}<r<R<1$. If $z=r e^{i \theta}$, we proceed in a similar manner to that above using the Poisson-Jensen formula to obtain $m_{2}(r, f)^{2}$. Further similar steps to the above along with the choice of $R=(1 / 2)(1+r)$ lead to the desired conclusion.

5. Proof of Theorem 4. We may assume without loss of generality that $f(0)=1$. It can be shown using Green's theorem as in [6] that if $f(z)=e^{g(z)}$ in $\{z|| z \mid \leqq r\}$, where $0<r<1$, then

$$
\begin{aligned}
& \frac{d}{d t}\left(\frac{1}{2 \pi} \int_{0}^{2 \pi}\left(\log \left|f\left(t e^{i \theta}\right)\right|\right)^{2} d \theta\right. \\
& \quad=\frac{1}{\pi t} \int_{0}^{t} \int_{0}^{2 \pi}\left|g^{\prime}\left(\rho e^{i \theta}\right)\right|^{2} \rho d \theta d \rho,
\end{aligned}
$$

for $0<t<r$. Integrating (5.1) from 0 to $r$, we obtain

$$
m_{2}(r, f)^{2}=\int_{0}^{r} \frac{1}{\pi t}\left(\int_{0}^{t} \int_{0}^{2 \pi}\left|\frac{f^{\prime}\left(\rho e^{i \theta}\right)}{f\left(\rho e^{i \theta}\right)}\right|^{2} \rho d \theta d \rho\right) d t .
$$

Using (1.2) in the right-hand side of (5.2), we find

$$
m_{2}(r, f)^{2}=\left\{\begin{array}{l}
0(1),(r \longrightarrow 1), \text { if } \beta \leqq 2 ; \\
0\left((1-r)^{-\beta+2}\right),(r \longrightarrow 1), \text { if } \beta>2 .
\end{array}\right.
$$


Since $\alpha>0$ and $\beta<2+2 \alpha$, we see that whatever the value of $\beta$ the statements in (5.3) lead to contradictions. Hence if $f$ satisfies the hypothesis of Theorem 4 , it must have at least one zero in $D$.

So suppose $f$ has zeros but that the number of zeros is finite. Let $\left\{a_{n}\right\}$ be the zeros, and assume $r_{0}$ is such that $\left|a_{n}\right|<r_{0}<1$, for all $n$. Define the function $B$ in $D$ by

$$
B(z)=\prod_{\left|a_{n}\right|<r_{0}}\left(\frac{z-a_{n}}{1-\bar{a}_{n} z}\right) .
$$

We consider $r_{0}<r_{1}<r<1$ and apply (5.1) to the function defined by the quotient $f / B$ in $D$. Integrating from 0 to $r$, we obtain

$$
\begin{aligned}
& m_{2}(r, f)^{2}= \frac{1}{\pi} \int_{0}^{2 \pi}\left(\log \left|f\left(r e^{i \theta}\right)\right|\right)\left(\log \left|B\left(r e^{i \theta}\right)\right|\right) d \theta \\
&+\frac{1}{2 \pi} \int_{0}^{2 \pi}\left(\log \left|B\left(r e^{i \theta}\right)\right|\right)^{2} d \theta+\left(\log \left|\frac{f(o)}{B(o)}\right|\right)^{2} \\
&+O(1)+\int_{r_{1}}^{r} \frac{1}{\pi t} \int_{r_{1}}^{t} \int_{0}^{2 \pi}\left|\frac{f^{\prime}\left(\rho e^{i \phi}\right)}{f\left(\rho e^{i \phi}\right)}-\frac{B^{\prime}\left(\rho e^{i \phi}\right)}{B\left(\rho e^{i \phi}\right)}\right|^{2} \rho d \phi d \rho d t, \\
&(r \longrightarrow 1) .
\end{aligned}
$$

Since the number of zeros of $f$ is finite and $r>r_{1}>r_{0}>\left|a_{n}\right|$, for each $n$, we see the first term on the right-hand side of (5.4) is bounded by

$$
O(T(r, f)), \quad(r \longrightarrow 1),
$$

and the second and third terms are bounded by a constant. Thus (5.4) becomes

$$
\begin{aligned}
& m_{2}(r, f)^{2} \leqq O(T(r, f)) \\
&+\int_{r_{1}}^{r} \frac{1}{\pi t} \int_{r_{1}}^{t} \int_{0}^{2 \pi}\left|\frac{f^{\prime}\left(\rho e^{i \phi}\right)}{f\left(\rho e^{i \phi}\right)}-\frac{B^{\prime}\left(\rho e^{i \phi}\right)}{B\left(\rho e^{i \phi}\right)}\right|^{2} \rho d \phi d \rho d t, \\
&(r \longrightarrow 1) .
\end{aligned}
$$

Using standard inequalities, we then get

$$
\begin{aligned}
m_{2}(r, f)^{2} \leqq & O(T(r, f))+\int_{r_{1}}^{r} \frac{1}{\pi t} \int_{r_{1}}^{t} \rho\left\{I_{2}(\rho)+\int_{0}^{2 \pi}\left|\frac{B^{\prime}\left(\rho e^{i \phi}\right)}{B\left(\rho e^{i \phi}\right)}\right|^{2} d \phi\right. \\
& \left.+2\left(I_{2}(\rho)\right)^{1 / 2}\left(\int_{0}^{2 \pi}\left|\frac{B^{\prime}\left(\rho e^{i \phi}\right)}{B\left(\rho e^{i \phi}\right)}\right|^{2} d \phi\right)^{1 / 2}\right\} d \rho d t, \quad(r \longrightarrow 1) .
\end{aligned}
$$

We know that

$$
\frac{B^{\prime}(z)}{B(z)}=\sum_{n}\left(\frac{1}{z-a_{n}}+\frac{\bar{a}_{n}}{1-\bar{a}_{n} z}\right)
$$

Hence the fact that 


$$
\int_{0}^{2 \pi} \frac{d \theta}{\left|1-s e^{i \theta}\right|^{2}}=0\left(\frac{1}{1-s}\right), \quad(s \longrightarrow 1),
$$

enables one to obtain the estimate

$$
\int_{0}^{2 \pi}\left|\frac{B^{\prime}\left(\rho e^{i \phi}\right)}{B\left(\rho e^{i \phi}\right)}\right|^{2} d \phi=0\left(\frac{1}{1-\rho}\right), \quad(\rho \longrightarrow 1) .
$$

We then observe

$$
\int_{r_{1}}^{r} \frac{1}{\pi t} \int_{r_{1}}^{t} \rho\left(\frac{1}{1-\rho}\right) d \rho d t \leqq \int_{r_{1}}^{r}\left(\log \frac{1}{1-t}\right) d t \leqq 1
$$

Taking (5.7) and (5.8) together with (5.6) we get

$$
\begin{aligned}
m_{2}(r, f)^{2} \leqq & 0(T(r, f))+0\left(\log \frac{1}{1-r}\right) \\
& +K \int_{r_{1}}^{r} \frac{1}{\pi t} \int_{r_{1}}^{t} \rho\left\{I_{2}(\rho)+\left(I_{2}(\rho)\right)^{1 / 2}\left(\frac{1}{1-\rho}\right)^{1 / 2}\right\} d \rho d t,
\end{aligned}
$$

$(\boldsymbol{r} \longrightarrow 1)$

Recalling that $\tilde{\alpha}<\alpha$ and that (1.2) holds, we see as in the earlier case (5.9) leads to a contradiction whatever the value of $\beta$ subject to $\beta<2+2 \alpha$ with $\alpha>0$. Therefore, $f$ has an infinite number of zeros.

\section{REFERENCES}

1. W. Hayman, Meromorphic Functions, Oxford University Press, 1964.

2. C. Linden, Integral means and zero distributions of Blaschke products, Canad. J. Math., 24 (1972), 755-760.

3. G. R. MacLane and L. Rubel, On the growth of Blaschke products, Canad. J. Math., 21 (1969), 595-600.

4. J. Miles and D. Shea, On the growth of meromorphic functions having at least one deficient value, Duke Math. J., 43 (1976), 171-186.

5. L. Rubel, A survey of Fourier series method for meromorphic functions, Springer Lecture Notes in Mathematics 336, (1973), 51-62.

6. L. R. Sons, Zeros of functions with slow growth in the unit disc, Math. Japonica, 24 (1979), 271-282.

Received July 30, 1980 and in revised form May 21, 1981.

NORTHERN ILLINOIS UNIVERSITY

DEKALB, IL 60115 



\title{
PACIFIC JOURNAL OF MATHEMATICS
}

\section{EDITORS}

\author{
DONALD BABBITT (Managing Editor) \\ University of California \\ Los Angeles, CA 90024 \\ Hugo RossI \\ University of Utah \\ Salt Lake City, UT 84112 \\ C. C. MOORE and Arthur Agus \\ University of California \\ Berkeley, CA 94720
}

\section{J. DugundjI}

Department of Mathematics

University of Southern California

Los Angeles, CA 90007

R. FinN and J. Milgram

Stanford University

Stanford, CA 94305

\section{ASSOCIATE EDITORS}
R. ARENS
E. F. BeCKENBACH
B. H. NeumanN
F. WOLF
K. YoshidA

\section{SUPPORTING INSTITUTIONS}

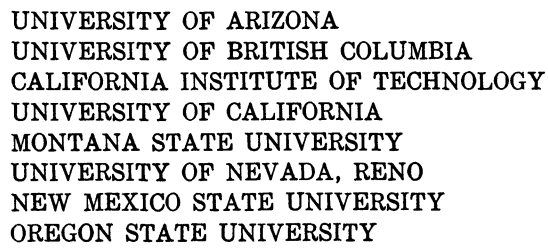

UNIVERSITY OF ARIZONA

UNIVERSITY OF BRITISH COLUMBIA

CALIFORNIA INSTITUTE OF TECHNOLOGY

UNIVERSITY OF CALIFORNIA

MONTANA STATE UNIVERSITY

UNIVERSITY OF NEVADA, RENO

NEW MEXICO STATE UNIVERSITY

OREGON STATE UNIVERSITY

\author{
UNIVERSITY OF OREGON \\ UNIVERSITY OF SOUTHERN CALIFORNIA \\ STANFORD UNIVERSITY \\ UNIVERSITY OF HAWAII \\ UNIVERSITY OF TOKYO \\ UNIVERSITY OF UTAH \\ WASHINGTON STATE UNIVERSITY \\ UNIVERSITY OF WASHINGTON
}

The Supporting Institutions listed above contribute to the cost of publication of this Journal, but they are not owners or publishers and have no responsibility for its content or policies.

Mathematical papers intended for publication in the Pacific Journal of Mathematics should be in typed form or offset-reproduced, (not dittoed), double spaced with large margins. Please do not use built up fractions in the text of the manuscript. However, you may use them in the displayed equations. Underline Greek letters in red, German in green, and script in blue. The first paragraph or two must be capable of being used separately as a synopsis of the entire paper. Please propose a heading for the odd numbered pages of less than 35 characters. Manuscripts, in triplicate, may be sent to any one of the editors. Please classify according to the scheme of Math. Reviews, Index to Vol. 39. Supply name and address of author to whom proofs should be sent. All other communications should be addressed to the managing editor, or Elaine Barth, University of California, Los Angeles, California, 90024.

50 reprints to each author are provided free for each article, only if page charges have been substantially paid. Additional copies may be obtained at cost in multiples of 50 .

The Pacific Journal of Mathematics is issued monthly as of January 1966. Regular subscription rate: $\$ 102.00$ a year (6 Vols., 12 issues). Special rate: $\$ 51.00$ a year to individual members of supporting institutions.

Subscriptions, orders for numbers issued in the last three calendar years, and changes of address shoud be sent to Pacific Journal of Mathematics, P.O. Box 969, Carmel Valley, CA 93924, U.S.A. Old back numbers obtainable from Kraus Periodicals Co., Route 100, Millwood, NY 10546.

\section{PUBLISHED BY PACIFIC JOURNAL OF MATHEMATICS, A NON-PROFIT CORPORATION}

Printed at Kokusai Bunken Insatsusha (International Academic Printing Co., Ltd.). 8-8, 3-chome, Takadanobaba, Shinjuku-ku, Tokyo 160, Japan. 


\section{Pacific Journal of Mathematics}

Vol. 99, No. $2 \quad$ June, 1982

Thomas E. Armstrong and Karel Libor Prikry, On the semimetric on a

Boolean algebra induced by a finitely additive probability measure . . . .249

Walter Russell Bloom, Strict local inclusion results between spaces of

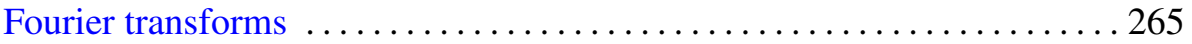

Richard Clark Brown, Notes on generalized boundary value problems in

Banach spaces. II. Infinite-dimensional extension theory ........... 271

Sui Sun Cheng, Isoperimetric eigenvalue problem of even order differential

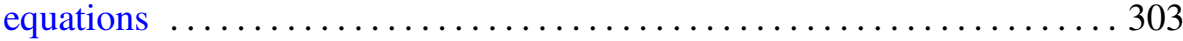

Lung O. Chung and Jiang Luh, Derivations of higher order and

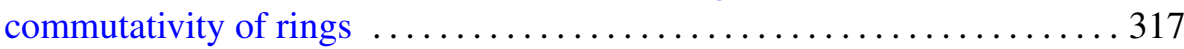

Ali Ahmad Fora, A fixed point theorem for product spaces . . . . . . . . . 327

Barry J. Gardner, Radical classes of regular rings with Artinian primitive

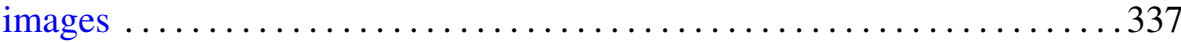

John Brady Garnett and Peter Wilcox Jones, BMO from dyadic BMO . . . 351

Allen E. Hatcher, On the boundary curves of incompressible surfaces . . . . 373

Richard Howard Hudson and Kenneth S. Williams, Resolution of

ambiguities in the evaluation of cubic and quartic Jacobsthal sums .....379

Viktor Losert, Counter-examples to some conjectures about doubly

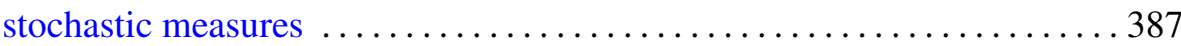

Kenneth Derwood Magill, Jr., P. R. Misra and Udai Bhan Tewari,

Structure spaces for sandwich semigroups

Mark Mandelker, Continuity of monotone functions

Kenneth Guy Miller, An index theorem and hypoellipticity on nilpotent Lie groups ......................................... 419

Evelyn M. Nelson, Homomorphisms of mono-unary algebras . . . . . . . . . 427

Marvin E. Ortel, The support of an extremal dilatation . . .

R. S. Pathak and O. P. Singh, Finite Hankel transforms of distributions . . . 439

Richard Cole Penney, The theory of ad-associative Lie algebras

Linda Ruth Sons, Zero distribution of functions with slow or moderate

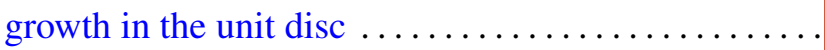

Russell Bruce Walker, Transversals to laminations 